\title{
Korean Atmospheric Environmental Impact Assessment for Thermal Power Plant
}

\author{
Young Soo Lee*, Ji Su Bae, Yu Jin Kang \\ Korea Environment Institute, Seoul, South Korea \\ Email: ${ }^{*}$ leeys@kei.re.kr, keileeys@gmail.com
}

Received May 2014

\begin{abstract}
Korea has adopted Environmental Impact Assessment (hereafter "EIA") system for more than 3 decades. There are 74 big projects subject to EIA according to (Environmental Impact Assessment Law (No. 10892). For thermal power plant of which output is more than $10 \mathrm{MW}$, EIA must be done by proponents. To assess impact on atmospheric environment, proponents utilize air dispersion models and to minimize the adverse impact on air quality, state-of-the-art add-on control technology is applied.
\end{abstract}

Keywords

Thermal Power Plant, Korean Atmospheric EIA Methodology

\section{Introduction}

Recently, Korea set up many thermal power plant construction plans and those constructions are subjects of EIA (Table 1).

During EIA negotiation procedures between Ministry of Environment and approval agency (ex. Ministry of Trade, Industry and Energy of Korea), Korea Environment Institute (hereafter "KEI”) reviews EIA reports, and gives opinions about power plant construction plans to Ministry of Environment in order to achieve sustainable development.

There are 6 review categories as follows:

1) Flora and fauna.

2) Atmospheric environment.

3) Water environment.

4) Land environment.

5) Life related environment.

6) Socio-economy environment.

Table 1. Thermal power plant construction plans in Korea.

\begin{tabular}{cccccc}
\hline Year & 2010 & 2011 & 2012 & Nov. 2013 & Total \\
\hline Case & 7 & 15 & 13 & 13 & 48 \\
\hline
\end{tabular}

How to cite this paper: Lee, Y. S., Bae, J. S., \& Kang, Y. J. (2014). Korean Atmospheric Environmental Impact Assessment for Thermal Power Plant. Journal of Geoscience and Environment Protection, 2, 25-27. 
In Atmospheric Environment, there are 4 review items such as meteorology, air quality, odor, and green house.

On the other hand, according to (Environmental Health Act (No. 12524)) human health impact due to power plant must be reviewed in EIA. So, for coal fired power plant, the adverse impact caused by heavy metals like $\mathrm{Cr}^{+6}$, Cd, Ni, Hg, As, Be on human health is examined.

In this paper, assessment methodology for air quality and human health of Korean EIA will be introduced.

\section{Assessment Methodology}

\subsection{Air Quality}

To assess adverse impact on air quality, concentrations of several air pollutants such as $\mathrm{SO}_{2}, \mathrm{NO}_{2}, \mathrm{PM}_{10}, \mathrm{PM}_{2.5}$, $\mathrm{Pb}, \mathrm{O}_{3}$, Benzene are calculated by air dispersion models. CALPUFF is widely used and for $\mathrm{O}_{3}, \mathrm{CMAQ}$ is used. Before modeling, meteorological data and emission amount of each air pollutant can be obtained. For meteorological data, on-site measurement (at least 1 year) and CALPUFF, WRF are used. For emission calculation, emission factor is used.

\subsection{Human Health}

To assess impact on human health, risk assessment is carried out. For carcinogenic materials, probability of cancer occurrence is calculated. The criterion is $10^{-6}$ ( 1 occasion among million people). For non-carcinogenic materials, exposure ratio (ER, concentration of each pollutant/standard concentration) is calculated. The criterion is 1. It means that when ER of a material exceeds 1, the adverse impact on health due to that pollutant is anticipated, so, the proponent must reduce the concentration of that pollutant.

By the way, human health impact is examined in Hygiene and Public Health item (not air quality) in whole EIA review process.

\subsection{Mitigation Measures}

To reduce $\mathrm{SO}_{2}, \mathrm{NO}_{2}$, PM and Heavy metals, wet type FGD (flue gas desulfurization), SCR (Selective Catalytic Reduction), ESP (Electro Static Precipitator) are commonly used, respectively.

Furthermore, the stack height is usually over $150 \mathrm{~m}$ for coal-fired power plant.

\subsection{Effect of EIA}

After negotiation between Ministry of Environment and Ministry of Trade, Industry and Energy, maximum emission concentrations of main pollutants are determined. Usually, those concentrations are more stringent than those of (Air Environment Conservation Act) (Table 2).

Proponent must meet the concentrations.

\section{Conclusion}

In this paper, we introduced outline of EIA, methodology of atmospheric impact assessment and mitigation

Table 2. Negotiation concentrations for power plant.

\begin{tabular}{|c|c|c|c|c|c|c|c|c|}
\hline & \multirow{2}{*}{ Case } & \multicolumn{2}{|c|}{$\mathrm{SO}_{2}$} & \multicolumn{2}{|c|}{$\mathrm{NO}_{2}$} & \multicolumn{2}{|c|}{$\mathrm{PM}$} & \multirow{2}{*}{ Date } \\
\hline & & Conc $1^{*}$ & Conc $2^{* *}$ & Conc 1 & Conc 2 & Conc 1 & Conc2 & \\
\hline \multirow{2}{*}{ Coal } & A & 70 & \multirow{2}{*}{80} & 60 & \multirow{2}{*}{80} & 15 & \multirow{2}{*}{20} & 2005 \\
\hline & B & 50 & & 35 & & 15 & & 2011 \\
\hline \multirow[b]{2}{*}{ LNG } & $\mathrm{C}$ & \multirow[b]{2}{*}{-} & \multirow[b]{2}{*}{ - } & 10 & \multirow[b]{2}{*}{50} & \multirow[b]{2}{*}{-} & \multirow[b]{2}{*}{-} & 2011 \\
\hline & $\mathrm{D}$ & & & 8 & & & & 2012 \\
\hline
\end{tabular}

$\overline{{ }^{*} \text { Conc1 means maximum emission concentration as a result of negotiation. }{ }^{* *} \text { Conc2 means emission standard regulated by (Air Environment Conser- }}$ vation Act). 
measures briefly. In Korea, Ministry of Environment has tried to achieve sustainable development through EIA and proponents do their best to reduce adverse effect on environment and human health with the aid of stateof-art add-on technologies for conservation of clean air.

\section{Acknowledgements}

This research is funded by Ministry of Environment of Korea and sponsored by Korea Electric Power Company (KEPCO). 